\title{
Advances in Murine Models of Diabetic Nephropathy
}

\author{
Li-li Kong, Hao Wu, Wen-peng Cui, Wen-hua Zhou, Ping Luo, Jing Sun, \\ Hang Yuan, and Li-ning Miao
}

Department of Nephrology, The Second Hospital of Jilin University, Changchun 130041, China

Correspondence should be addressed to Li-ning Miao; miaolining@yahoo.com.cn

Received 2 February 2013; Accepted 21 May 2013

Academic Editor: Shahidul Islam

Copyright (C) 2013 Li-li Kong et al. This is an open access article distributed under the Creative Commons Attribution License, which permits unrestricted use, distribution, and reproduction in any medium, provided the original work is properly cited.

\begin{abstract}
Diabetic nephropathy (DN) is one of the microvascular complications of both type 1 and type 2 diabetes, which is also associated with a poor life expectancy of diabetic patients. However, the pathogenesis of DN is still unclear. Thus, it is of great use to establish appropriate animal models of $\mathrm{DN}$ for doing research on pathogenesis and developing novel therapeutic strategies. Although a large number of murine models of DN including artificially induced, spontaneous, and genetically engineered (knockout and transgenic) animal models have been developed, none of them develops renal changes sufficiently reflecting those seen in humans. Here we review the identified murine models of DN from the aspects of genetic background, type of diabetes, method of induction, gene deficiency, animal age and gender, kidney histopathology, and phenotypic alterations in the hope of enhancing our comprehension of genetic susceptibility and molecular mechanisms responsible for this disease and providing new clues as to how to choose appropriate animal models of DN.
\end{abstract}

\section{Introduction}

$\mathrm{DN}$, as one complication of diabetes, is one of the leading causes of end-stage renal disease (ESRD) worldwide. The value of animal models in the study of pathogenesis is beyond doubt. Although great progress has been made in the study of animal models, none of the models can reproduce all the structural and functional changes of human DN. Murine models have substantial advantages over other species in the studies on pathogenesis of $\mathrm{DN}$, including lower cost, murine repositories that bear multiple mutations, plentiful inbred strains, and an available map of murine genomic sequence on the Internet. The Animal Models of Diabetic Complications Consortium (AMDCC) proposes the following three criteria for a desirable murine model of DN: (1) more than 50\% decline in glomerular filtration rate (GFR) over the lifetime of the animal; (2) greater than 10-fold increase in albuminuria compared with controls for that strain at the same age and gender; (3) histopathology findings which include mesangial sclerosis (a 50\% increase in mesangial volume), any degree of arteriolar hyalinosis, glomerular basement membrane (GBM) thickening (a $>25 \%$ increase compared with baseline by electron microscopy morphometry), and tubulointerstitial fibrosis. In fact, there are no murine models that meet all of the three criteria. Here we review the identified murine models of DN including artificially induced, spontaneous, and genetically engineered (knockout and transgenic) animal models and compare their advantages and deficiencies. Some of the key issues, such as strain, genetic background, type of diabetes, method of induction, gene deficiency, animal age and gender, kidney histopathology, and phenotypic alterations, are all included in this review. We hope this review could enhance our understanding of genetic susceptibility and molecular mechanisms responsible for DN, as well as provide new clues as to how to choose appropriate animal models of DN.

\section{Artificially Induced Murine Models of DN}

2.1. Murine Models of DN from Type 1 Diabetes Mellitus (T1DM). Alloxan and streptozotocin (STZ) are widely used for producing artificially induced T1DM which causes kidney damage with similarities to human DN. Both of them are glucose analogues that enter the insulin-producing beta-cells via a glucose transporter. The diabetogenic actions of alloxan and 
STZ are mediated by reactive oxygen species (ROS). However, they are generated through different approaches in the case of alloxan and STZ. In the presence of glutathione, alloxan and its reduction product, dialuric acid, generate superoxide radicals in a cyclic redox reaction which undergo dismutation to hydrogen peroxide afterwards. Then Fenton reaction ensues with the formation of highly reactive hydroxyl radicals. After being taken into pancreatic beta-cells, STZ is broken down into its glucose and methylnitrosourea moiety. The latter modifies DNA fragments due to its alkylating properties. DNA damage causes the activation of poly ADPribosylation which leads to depletion of cellular $\mathrm{NAD}^{+}$and ATP. Enhanced ATP dephosphorylation provides substrate for xanthine oxidase. As a result, superoxide radicals are formed. ROS and a simultaneous cytosolic calcium overload lead to acute necrosis of pancreatic beta-cells $[1,2]$. So both of the two diabetogenic agents induce diabetes secondary to the necrosis of pancreatic beta-cells. As time progresses, hyperglycaemia eventually leads to diabetic kidney damage. These STZ-treated models develop a modest degree of proteinuria and serum creatinine increase, as well as minimal mesangial matrix expansion, depending on the genetic background [3, 4]. Animal models of STZ-induced DN are usually performed in mice, Sprague-Dawley and Wistar-Kyoto rats.

2.1.1. Moderate and High-Dose STZ. Given the mouse strains which are resistant to a single dose of STZ $(\geq 200 \mathrm{mg} / \mathrm{kg})$ or a two-dose regimen of STZ $(2 \times 100-2 \times 125 \mathrm{mg} / \mathrm{kg})$, greater cytotoxicity to pancreatic beta-cells and collateral tissue occurs, resulting in a higher incidence and severity of diabetes [4-7]. Because of the severe hyperglycaemia, the diabetic models need to be monitored for blood glucose and administrated insulin. Several months later, a modest degree of proteinuria can be detected. Some investigators optimize the animal models of STZ-induced DN by uninephrectomy in advance which lead to compensatory hypertrophy of the remaining kidney and acceleration of the disease progression. However, owing to the nephrotoxicity of STZ, it is difficult to differentiate between the direct toxic effect of STZ and lesions caused by hyperglycaemia $[8,9]$. Some studies on mouse models of DN show that high-dose STZ-treated mice exhibit more albuminuria than those which receive low-dose STZ, despite of similar blood glucose [10]. Besides, evidence for acute kidney injury caused by high-dose STZ in mice and rats has been reported $[9,11]$. Although STZ-treated models result in hypoinsulinemia and hyperglycaemia, they do not share autoimmune features like patients with T1DM.

2.1.2. Low-Dose STZ. In order to reduce nonspecific nephrotoxicity of STZ, the regimen of multiple low-dose injections of STZ to induce diabetes has been performed, that is daily intraperitoneally injections of $40-60 \mathrm{mg} / \mathrm{kg}$ STZ for five consecutive days $[4,12-14]$ which usually induces repetitive low-grade beta cell damage accompanied by secondary autoimmune insulitis $[15,16]$. It is quite different among inbred strains of mice in susceptibility to both pancreatic beta cell toxicity [17] and the direct nephrotoxicity of lowdose STZ [12]. It is reported by Gurley et al. [18] that there is a hierarchical response of blood glucose level to multiple low doses of STZ (DBA/2 > C57BL/6 > MRL/MP > $129 / \mathrm{SvEv}>\mathrm{BALB} / \mathrm{c})$. His research results also show that males are more susceptible to diabetes induced by this STZ regimen than females. Generally, given strain-appropriate doses of STZ, mice that receive low-dose STZ develop parallel levels of hyperglycemia to those that receive highdose STZ [9]; the levels of albuminuria, by contrast, are generally lower as a result of reduced direct nephrotoxicity of STZ [19, 20]. Moreover, evidence for nontoxicity on podocytes has been reported. The US-based AMDCC also recommends a standard low-dose model for STZ-induced diabetic complications which include DN. According to this recommendation, mouse models of $\mathrm{DN}$ should be induced by daily intraperitoneally injections of $50 \mathrm{mg} / \mathrm{kg} \mathrm{STZ} \mathrm{for} \mathrm{five}$ consecutive days. However, studies show that only $50 \%$ of C57BL/ 6 mice develop overt diabetes through this approach. Therefore, whether it will be adopted by relevant experts is not yet determined.

2.2. Murine Models of DN from Type 2 Diabetes Mellitus (T2DM). The protocol of high-fat diet is widely used to induce insulin resistance and obesity [21-23]. It is also of great use for the research of accelerated atherosclerosis [24-26], although inbred strains of mice exhibit significant differences in response to the effect of high-fat diet. C57BL6 mice respond strongly to high-fat diet; A/J mice, by contrast, are relatively resistant [21]. Sugano et al. [27] have reported a new rat model of DN induced by high-fat diet, multiple lowdose injections of STZ, and uninephrectomy. This model exhibits most features of human DN from T2DM including hyperglycemia, hypoinsulinemia, hyperlipidaemia, hypertension, and microalbuminuria followed by overt albuminuria, mesangial expansion, and terminal glomerular sclerosis.

\section{Spontaneous Murine Models of DN}

Spontaneous animal models of DN are established by selective breeding from animals which spontaneously develop DN due to genetic abnormality. Renal abnormalities in these models resemble human diseases; therefore, these models provide an experimental platform for studying pathogenesis and genetic susceptibility responsible for DN. Although these models are difficult to feed and breed, not widely available, and with long modeling cycle and higher cost, the application of them is becoming increasingly extensive. Table 1 lists some common murine models of spontaneous DN.

\subsection{Murine Models of Spontaneous DN from T1DM}

3.1.1. Nonobese Diabetic (NOD) Mouse. The spontaneous murine model of T1DM that has been studied most extensively is the NOD mouse. Due to pathogenic and genetic similarities to the human disease, the model serves as a useful tool to study the etiology, pathology, and progression of disease. NOD mouse was derived from the Jcl: ICR cataract mouse 30 years ago in Japan [28]. These mice develop spontaneous insulitis at the age of 4-5 weeks, and overt 


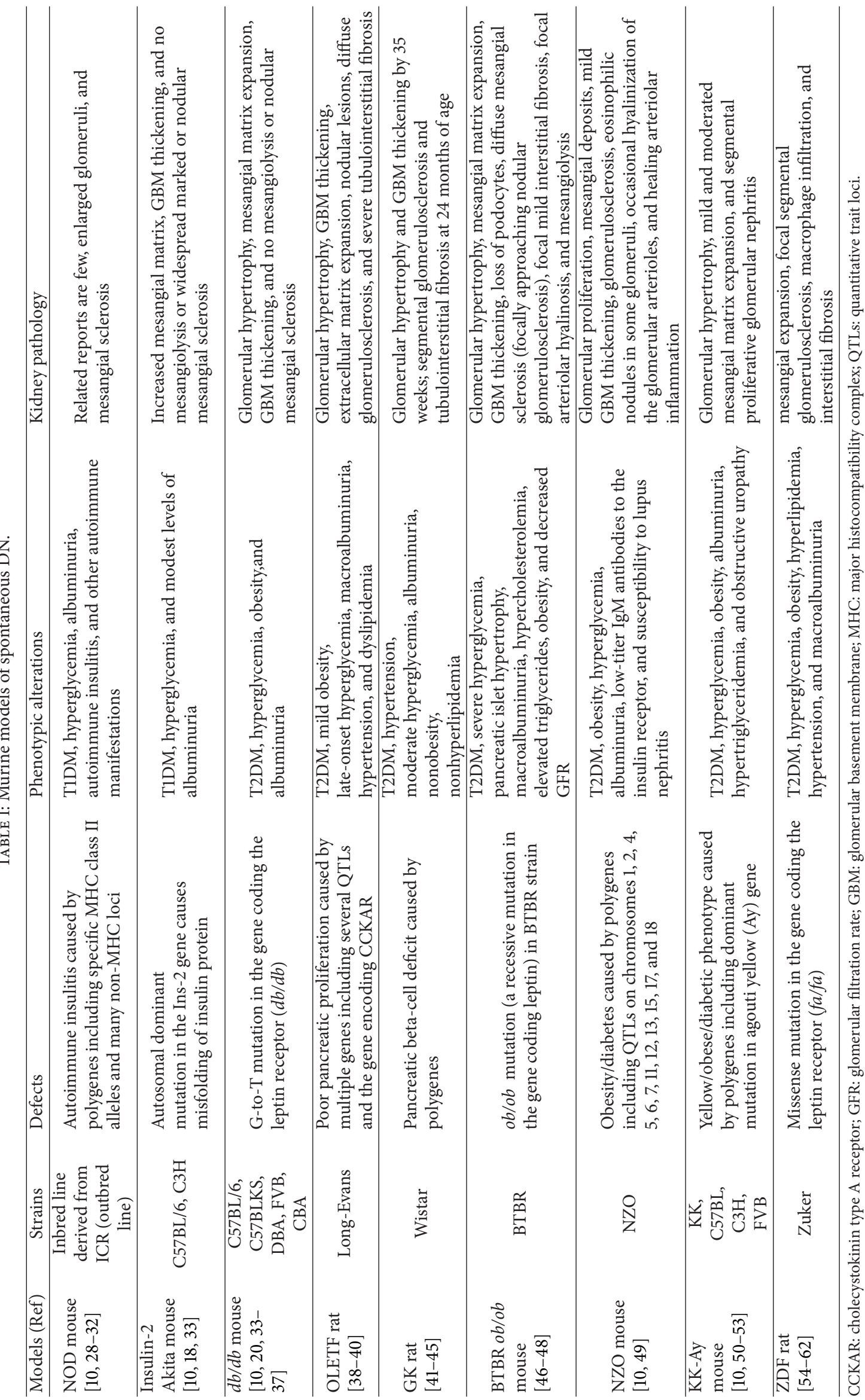


diabetes emerges at the age of 24-30 weeks when most of pancreatic $\beta$-cells are destroyed. Female incidence of diabetes is four times higher than the male in NOD mice [10]. This model exhibits a number of clinical features of human T1DM including hyperglycaemia, glycosuria, polyuria, and polydipsia; however, it is more resistant to ketoacidosis. Without insulin administration, NOD mice usually die of dehydration, rather than ketoacidosis. Like in humans, the major histocompatibility complex (MHC) alleles are closely related to susceptibility to T1DM. Moreover, some MHC alleles must be accompanied by other non-MHC genes for the development of T1DM [29,30], which is also the same in human disease. Even so, NOD mice are not the perfect animal model for human T1DM. As an inbred strain, they have a fixed genetic risk for T1DM and develop T1DM in a predictable fashion [31], whereas human T1DM develops as a result of deleterious interactions between relevant genes and from external environmental factors.

Despite of the extensive study of the genetic and immunologic pathogenesis of T1DM in NOD mouse, few investigators choose NOD mouse to do research on DN because of the complicated genetics, the late and variable age of onset of T1DM, and the requirement for insulin administration [10]. Even so, one of the few studies shows that the amount of albuminuria in hyperglycemic NOD mice is seven times higher than that in NOD mice before the development of hyperglycemia [32]. The results of renal lesions in acute phase of T1DM in NOD mice show mild changes in glomeruli and structural alteration of the proximal straight tubules. The study also points out that increased neuronal nitric oxide synthase may represent one of the pathogenic factors of DN [70]. Besides, there are also studies using NOD mice demonstrating that transforming growth factor- $\beta$ (TGF- $\beta$ ) and advanced glycosylation endproducts (AGE) take an important role in mesangial proliferation and sclerosis [7173], which is also the same in human DN.

3.1.2. Insulin-2 Akita Mouse. Akita mice develop T1DM because of the spontaneous mutation in Ins- 2 gene. The mutation leads to the misfolding of insulin protein, which is toxic to pancreatic $\beta$-cell. Consequently, the capacity of $\beta$ cell to secrete insulin is largely decreased. The Ins-2 Akita mutation which is autosomal dominant was originally found in C57BL/6 mice in Akita, Japan. Mice heterozygous for the mutation develop significant hyperglycemia as a result of severe insulin deficiency at 3 to 4 weeks of age, but homozygotus mice usually die in perinatal period. Males develop substantially worse insulin deficiency than females. Mice with Ins-2 Akita mutation exhibit modest levels of albuminuria and mild-to-moderate glomerular mesangial expansion [18]. Nonetheless, Akita mice have higher levels of hyperglycemia, albuminuria, blood pressure, and more consistent structural changes of kidney compared with STZ-induced DN [18]. Gurley et al. have found that renal phenotype of Akita mice is largely dependent on their genetic background strains [18]. It means that genetic factors might influence susceptibility to $\mathrm{DN}$ in Akita mice which is the same in human disease. Thus, mice bearing Ins-2 Akita mutation have significant advantages as a model of T1DM.

\subsection{Murine Models of Spontaneous DN from T2DM}

3.2.1. $\mathrm{Db} / \mathrm{db}$ Mouse. The $d b / d b$ mouse which has a G-to-T mutation in the gene coding the leptin receptor develops obesity, insulin resistance, and T2DM spontaneously. The $d b / d b$ mutation which is autosomal recessive was initially recognized from an obese and hyperphagic mouse in the C57BLKS/J strain and was subsequently backcrossed to a pure C57BL/6J background. Mice in the C57BLKS/J stain exhibit hyperinsulinemia at 10 days of age and slight hyperglycemia at 1 month of age. Overt hyperglycemia is noted by 8 weeks of age [20]. Manifestations of DN are albuminuria, glomerular hypertrophy, mesangial matrix expansion, and GBM thickening [20]. Albuminuria can be detected as early as 3 to 4 weeks after the onset of hyperglycemia [3]. The level of albuminuria in the $d b / d b$ male mouse is $68-600 \mu \mathrm{g} / 24 \mathrm{~h}$ $[20,34-37]$ which is only $4-21 \mu \mathrm{g} / 24 \mathrm{~h}[34,37]$ in the agematched heterozygous littermate. The $d b / d b$ mice display an increase in glomerular size and mesangial matrix by $5-6$ months of age [20]. By 18-20 months, the glomerular and mesangial matrix enlargements become more remarkable, and thickening of the GBM is observed [20]. In general, $d b / d b$ mice do not develop mesangiolysis, nodular mesangial sclerosis, and progressive renal insufficiency [33]. However, they are good models of early changes in human DN. Hyperglycemia, and renal changes of $d b / d b$ mice in C57BLKS/J stain are usually worse than in the C57BL/6 background. Hence, investigations of $\mathrm{DN}$ in $d b / d b$ mice are more widely conducted with the C57BLKS/J strain. Nonetheless, $d b / d b$ mice in the C57BL/6 stain which have been intercrossed with gene knockout and transgenic mice $[74,75]$ provide new strains to identify pathogenesis of DN.

3.2.2. Otsuka Long-Evans Tokushima Fatty (OLETF) Rat. The OLETF rat is an identified murine model of T2DM. The model is characterized by hyperphagia, mild obesity, late-onset hyperglycemia, hypertension, dyslipidemia and advanced DN. Multiple recessive genes are associated with the induction of diabetes, including $o d b-1$ on X-chromosome of OLETF rats. It is also reported that a major quantitative trait locus colocalizing with cholecystokinin type A receptor gene influences poor pancreatic proliferation in OLETF rats [38]. The progression of T2DM in OLETF rats can be prevented by exercise [76] and calorie-restricted diet [77] as human disease. At 12-20 weeks of age, OLETF rats exhibit mild obesity and hyperinsulinemia [39]. Late-onset hyperglycemia is noted by 18 weeks of age [39]. At 22 weeks of age, the OLETF rats develop overt albuminuria, and at 54 weeks, advanced renal changes such as macroalbuminuria, nodular lesions, diffuse glomerulosclerosis, and tubulointerstitial fibrosis are noted like human DN [40]. Therefore, OLETF rat is considered as one of the best murine models to study DN.

3.2.3. GK Rat. Goto Kakizaki (GK) rat, a spontaneous polygenic model of T2DM, is established by repeated inbreeding of glucose-intolerant Wistar rats over many generations [78]. This model is characterized by moderate hyperglycemia, peripheral insulin resistance, and nonhyperlipidemia, and 
nonobese phenotype. It is recognized that T2DM in GK rat is primarily caused by beta-cell deficit. In order to identify the origin of the abnormality, Miralles and Porthe [79] compared the development of the embryo in GK and Wistar rats. They found a decrease in pancreatic cell proliferation from embryonic day 16 to 20 (E16-E20) and a wave of pancreatic cell apoptosis from E16 to E18. By E16, the number of pancreatic beta-cells in the GK rats is half of the Wistar rats, and this difference was sustained until birth. GK rat exhibits morphological changes which can be seen in early stage of human DN such as glomerular hypertrophy and GBM thickening [41]. It does not develop overt proteinuria or progressive nephropathy by 8 months of age [41], even being treated with some initiators to promote renal injury [42, 43]. However, Sato et al. [44] have reported advanced renal changes in GK rats such as segmental glomerulosclerosis and tubulointerstitial fibrosis at 24 months of age. At that time, albuminuria increases notably. Thus, they draw the conclusion that renal changes in GK rats at a late stage were similar to those of progressive human DN. Therefore, GK rat serves a useful tool for studying T2DM and DN.

3.2.4. Ob/ob and BTBR ob/ob Mice. Compared with $d b / d b$ mouse, $o b / o b$ mouse develops T2DM caused by the spontaneous recessive mutation in leptin [46], the ligand for the leptin receptor. The $o b / o b$ mutation exists in C57BL/6J, DBA2/J, and FVB strains. This model exhibits only mild functional and morphological changes in C57BL/6J strains [80]. Thus, it is not widely used as an animal model of DN.

However, a new mouse model that mimics progressive DN has been developed in BTBR strain with the $o b / o b$ mutation [47]. Its characteristics are insulin resistance, hyperinsulinemia, pancreatic islet hypertrophy, severe hyperglycemia, obesity, hypercholesterolemia, and elevated triglycerides. The BTBR $o b / o b$ mice are largely resistant to the hypoglycemic effect of insulin administration and rapidly develop pathological changes of both early and advanced human DN [48]. The mice develop progressive proteinuria by 4 weeks of age. Characteristics of early DN such as glomerular hypertrophy, accumulation of mesangial matrix, and loss of podocytes are detectable by 8 weeks of age [48]. Glomerular lesions of progressive, advanced DN are present by 20 weeks. By 22 weeks, morphological characteristics of renal injury has $20 \%$ increase in GBM thickness, $50 \%$ increase in mesangial matrix, mesangiolysis, diffuse mesangial sclerosis, focal arteriolar hyalinosis, and focal mild interstitial fibrosis [48]. On the one hand, the advantage of BTBR ob/ob mice over other animal models is the relatively short period for the development of advanced DN. On the other hand, compared with $d b / d b$ mice (with deficiency of the leptin receptor), BTBR $o b / o b$ mice provide a new tool for testing therapeutic effect of leptin administration in DN, whereas the mice have apparent limitations, such as their high cost and infertility [33]. Besides, due to the limited study on BTBR strain, investigators have to pay great attention to the time-consuming backcrossing strategies in order to induce specific genetic mutations into these mice [33]. Nonetheless, BTBR $o b / o b$ mouse is fairly valuable for testing therapeutic interventions.
3.2.5. New Zealand Obese (NZO) Mouse. The NZO mouse is established by selective breeding from polygenic mice of obesity and T2DM in New Zealand. It is characterized by obesity, T2DM, and low-titer IgM antibodies to the insulin receptor [49]. The QTLs on chromosomes 1, 2, 4, 5, 6, 7, 11, $12,13,15,17$, and 18 [81-83] are responsible for the disease. NZO mice are prone to autoimmune disease and develop circulating antibodies to both native DNA and single-stranded DNA [49]. By 6 months of age, the antibody levels in NZO mice are comparable to those found in the mouse models of systemic lupus erythematosus [49]. NZO mice exhibit morphological features of both diabetic and lupus nephropathies, such as glomerular proliferation, mesangial deposits, mild GBM thickening, glomerulosclerosis, eosinophilic nodules in some glomeruli, occasional hyalinization of the glomerular arterioles, and healing arteriolar inflammation [49]. Thus, given the evidence of immune disorder, NZO mouse offers a unique opportunity to study the relationship among T2DM, autoimmunity, and obesity.

3.2.6. KK-Ay Mouse. KK-Ay mice develop T2DM caused by the dominant mutation in agouti yellow (Ay) gene. The Ay gene is expressed in the hair follicle, where the gene product acts as an antagonist of melanocyte stimulating hormone receptor resulting in the inhibition of melanogenesis and yellow fur [50]. Besides, an agouti-related protein influences weight regulation [51]. It is widely recognized that Ay gene is crucial to the yellow obese phenotype. KK-Ay mice spontaneously exhibit severe, early-onset hyperinsulinemia, hyperglycemia, obesity, hypertriglyceridemia, fatty liver, and albuminuria. KK-Ay mice develop morphological changes of early DN, such as glomerular hypertrophy, mild and moderated mesangial matrix expansion, and segmental proliferative glomerular nephritis [52]. Therefore, KK-Ay mouse might be a useful murine model of the early stage of DN. It is notable, though, that most of male KK-Ay mice die of obstructive uropathy associated with hydronephrosis between 7 and 14 months of age without unknown causes [53]. Partly for this reason, KK-Ay mouse is not widely used as animal model of DN.

3.2.7. Zucker Diabetic Fatty (ZDF) Rat. The ZDF rat which has a missense mutation in the gene coding the leptin receptor (fa/fa) [54] spontaneously develops insulin resistance, T2DM, hyperlipidemia, both moderate hypertension and obesity, and progressive renal injury. Studies of the ZDF rats show that the hyperglycemia is sexually dimorphic. Although female ZDF rats have similar levels of insulin resistance and degrees of obesity to male ZDF rats, they develop hyperglycaemia only when administered with diabetogenic diet [84]. Thus, the ZDF male rats are more widely used as the animal models of T2DM and DN. Histopathologic changes of kidney [55-60] have been described as focal segmental glomerulosclerosis, mild mesangial expansion, macrophage infiltration, and interstitial fibrosis. Hyperglycaemia in ZDF rats is manifested by 12 weeks [61]. These rats develop albuminuria at 14 weeks [62] and focal segmental glomerulosclerosis at 1820 weeks of age [56, 57]. Macroalbuminuria ultimately leads to chronic renal insufficiency by 22 weeks of age [62]. The 
TABLE 2: Genetically engineered murine models of DN.

\begin{tabular}{|c|c|c|c|c|}
\hline Models (Ref) & Strains & Molecular background & Phenotypic alterations & Kidney pathology \\
\hline OVE26 mice [63-65] & FVB & $\begin{array}{l}\beta \text {-cell-specific damage due } \\
\text { to overexpression of } \\
\text { calmodulin transgene } \\
\text { regulated by the insulin } \\
\text { promoter }\end{array}$ & $\begin{array}{l}\text { T1DM, hyperglycemia, } \\
\text { hypertension, albuminuria, } \\
\text { hypoalbuminemia, and } \\
\text { GFR increased first and } \\
\text { then decreased }\end{array}$ & $\begin{array}{l}\text { Enlarged glomeruli, enlarging } \\
\text { mesangium with diffuse and nodular } \\
\text { expansion of mesangial matrix, GBM } \\
\text { thickening, diffuse and nodular } \\
\text { glomerulosclerosis, nodules similar to } \\
\text { typical K-W nodules, expansion of the } \\
\text { tubules, atrophy of tubular cells, } \\
\text { interstitial infiltration of mononuclear } \\
\text { cells, tubulointerstitial fibrosis }\end{array}$ \\
\hline $\begin{array}{l}\mathrm{eNOS}^{-/-} / d b / d b \text { mice } \\
{[66-68]}\end{array}$ & $\begin{array}{l}\mathrm{C} 57 / \mathrm{B} 6 \times \\
\mathrm{C} 57 \mathrm{BLKS} / \mathrm{J} \\
(\mathrm{BKS})\end{array}$ & $\begin{array}{l}\text { BKS- } d b / d b \text { mice cross with } \\
\text { eNOS }^{-1-} \text { mice }\end{array}$ & $\begin{array}{l}\text { T2DM, obesity, } \\
\text { hyperglycemia, } \\
\text { hypertension, albuminuria, } \\
\text { and decreased GFR }\end{array}$ & $\begin{array}{l}\text { Mesangial expansion, GBM thickening, } \\
\text { arteriolar hyalinosis, mesangiolysis, } \\
\text { microaneurysms, focal segmental and } \\
\text { nodular glomerulosclerosis, nodules that } \\
\text { resemble K-W nodules, striking } \\
\text { fibronectin accumulation in glomeruli, } \\
\text { minimal tubulointerstitial fibrosis }\end{array}$ \\
\hline
\end{tabular}

\begin{tabular}{|c|c|c|c|c|}
\hline $\begin{array}{l}\text { RAGE/iNOS mice } \\
{[45]}\end{array}$ & CD-1 & $\begin{array}{l}\text { Transgenic mice that } \\
\text { overexpress human RAGE } \\
\text { in vascular cells crossbreed } \\
\text { with another transgenic } \\
\text { line carrying human cDNA } \\
\text { for iNOS under the control } \\
\text { of the insulin promoter }\end{array}$ & $\begin{array}{l}\text { T1DM, } \\
\text { hyperglycemia, } \\
\text { albuminuria, and increased } \\
\text { serum creatinine }\end{array}$ & $\begin{array}{l}\text { Mesangial expansion, } \\
\text { diffuse glomerulosclerosis }\end{array}$ \\
\hline $\begin{array}{l}\text { Megsin/RAGE/iNOS } \\
\text { mice [69] }\end{array}$ & $\begin{array}{l}\mathrm{C} 57 \mathrm{BL} / 6 \mathrm{~N} \times \\
\mathrm{CD} 1\end{array}$ & $\begin{array}{l}\text { Triple transgenic mice } \\
\text { overexpressing megsin, } \\
\text { RAGE, and iNOS (megsin } \\
\text { transgenic mice crossbreed } \\
\text { with RAGE/iNOS } \\
\text { transgenic mice) }\end{array}$ & $\begin{array}{l}\text { T1DM, } \\
\text { hyperglycemia, } \\
\text { albuminuria, increased } \\
\text { serum creatinine, and urea } \\
\text { nitrogen }\end{array}$ & $\begin{array}{l}\text { Glomerular hypertrophy, diffuse } \\
\text { mesangial expansion, GBM thickening, } \\
\text { global mesangial sclerosis, some } \\
\text { segmental sclerotic lesions that resemble } \\
\text { K-W nodules, inflammatory cell } \\
\text { infiltration, interstitial fibrosis, and } \\
\text { immune complexes depositions }\end{array}$ \\
\hline
\end{tabular}

eNOS: endothelial nitric oxide synthase; GBM: glomerular basement membrane; GFR: glomerular filtration rate; iNOS: inducible nitric oxide synthase; K-W nodules: Kimmelstiel-Wilson nodules; RAGE: the receptor for advanced glycation endproducts.

ZDF rat exhibits a physiological and metabolic profile similar to human T2DM and functional and morphological renal lesions that resemble human DN. Thus, ZDF rat is considered as an excellent animal model of T2DM and DN.

\section{Genetically Engineered (Knockout and Transgenic) Murine Models of DN}

Diabetes is the major cause of ESRD worldwide. Despite of the high incidence, only a minority of patients with diabetes develop renal lesions. Family-based studies show that a significant genetic component confers risk for DN. All the above studies indicate the importance of genetic factors in differential susceptibility to DN, whereas limited progress has been made in identifying specific genetic factors that contribute to DN due to genetic heterogeneity and multigenic pathogenesis. Recently, investigators have developed genetically engineered murine models in combination with genetic manipulations, including transgenic and knockout mice bearing defined alterations in a single gene or in a series of candidate genes. Studies in vivo using these models show that the genes coding TGF- $\beta$, plasma prorenin, inducible
cAMP early repressor, receptor for advanced glycation endproducts (RAGE), endothelial nitric oxide synthase (eNOS), and aldose reductase involve in the origin and progression of DN, corroborating experimental findings from human association studies. Genetically engineered murine models provide valuable insight into the role of pathogenetic genes and molecular mechanisms responsible for DN, thus opening new avenues to develop novel therapeutic strategies. Table 2 lists some of the genetically engineered murine models that develop advanced DN-like human disease. Here we emphasize more on the OVE26 and the $\mathrm{eNOS}^{-/-} / d b / d b$ mice, of type 1 and type 2 diabetes, that develop kidney injury most resembling that seen in human.

4.1. OVE26 Mouse. The OVE26 mouse on the FVB inbred strain is a transgenic mouse model of severe early-onset type 1 diabetes [63]. These mice exhibit severe hyperglycemia 2-3 weeks after birth due to $\beta$-cell-specific damage in response to overexpression of calmodulin transgene regulated by the insulin promoter. Zheng et al. has reported progressively increasing albuminuria which is $305 \mu \mathrm{g} / 24 \mathrm{~h}$ by 2 months and $15,000 \mu \mathrm{g} / 24 \mathrm{~h}$ by 9 months of age [64]. They also detect hypoalbuminemia, increased GFR from 2-3 months, and the 
following decreased GFR from 5-9 months, as well as hypertension which coincided with increasing albuminuria. The OVE26 mice develop morphological changes of advanced DN including enlarged glomeruli, enlarging mesangium with diffuse and nodular expansion of mesangial matrix, GBM thickening, diffuse and nodular glomerulosclerosis, nodules similar to typical K-W nodules, expansion of the tubules, atrophy of tubular cells, interstitial infiltration of mononuclear cells, and tubulointerstitial fibrosis. A low level of pancreatic beta cell survival allows OVE26 mice to survive well over a year with no insulin treatment and maintain near normal body weight. The functional and morphological changes in OVE26 mice closely resemble human DN. Therefore, OVE26 mice provide a valuable model of advanced human DN. However, severe albuminuria in OVE26 mice highly depends on FVB background. Albuminuria, mesangial matrix expansion, and fibrosis are all significantly diminished when OVE26 mice were crossbred with C57BL6 or DBA2 mice [65]. This strain dependence makes it difficult to introduce other genetic mutations from other backgrounds into this model.

4.2. eNOS $^{-/-} / d b / d b$ Mouse. The eNOS ${ }^{-/-} / d b / d b$ mouse is a model of type 2 diabetes generated by backcrossing of eNOS knockout mouse on the C57/B6 background with $d b / d b$ mouse on the C57BLKS/J (BKS) background [66]. The $\mathrm{eNOS}^{-/-} / \mathrm{lepr}^{\mathrm{db} / \mathrm{db}}$ double-knockout mice exhibit obesity, hyperglycemia, hyperinsulinemia, hypertension, dramatic albuminuria, and decreased GFR $[67,68]$. These mice develop histopathological changes of DN-like human disease such as mesangial expansion, GBM thickening, mesangiolysis, focal segmental and nodular glomerulosclerosis, nodules that resemble K-W nodules, striking fibronectin accumulation in glomeruli, arteriolar hyalinosis, minimal tubulointerstitial fibrosis, and microaneurysms. These features establish this mouse model as one of the very few to develop features of advanced DN.

\section{Conclusions}

With increasing incidence of $\mathrm{DN}$, development of an ideal animal model becomes one of the top priorities in combating this health crisis. Murine models have significant advantages over other species in pathogenesis investigation. Impact of genetic background on several murine models of $\mathrm{DN}$ is evident on the susceptibility to diabetes-associated renal injury, the severity and histopathology of renal lesions. STZ-treated mice and rats are widely used as animal models of early DN due to their cost effectiveness and the absence of advanced pathological lesions. Some mutations in spontaneous murine models enhance our understanding of pathophysiological mechanisms of DN. Genetic engineering enables us to insert or delete a specific gene or a series of candidate genes, providing valuable insight into the role of pathogenetic genes and molecular mechanisms responsible for $\mathrm{DN}$, as well as opening new avenues to develop novel therapeutic strategies. However, it is difficult to establish an animal model that recapitulates all the features of human DN. Few models develop morphologically advanced DN; among these, OLETF rats, OVE26 mice, BTBR ob/ob mice, $\mathrm{eNOS}^{-1-} / d b / d b$ mice, RAGE/iNOS mice, and megsin/RAGE/iNOS mice seem to be the most robust. Perhaps the last four models suggest to us that more robust murine models of DN can be established by superimposed genetic mutations or crossbreeding with an entirely different strain. Novel animal models that reproduce human DN have yet to be established in the future.

\section{Acknowledgments}

The authors would like to express their gratitude to all the physicians participating in this work. The authors declare no conflict of interests. This study was supported by the National Natural Science Foundation of China (81170669, 81000300 , and 81200525) and Natural Science Foundation of Jilin Province (201215068).

\section{References}

[1] T. Szkudelski, "The mechanism of alloxan and streptozotocin action in B cells of the rat pancreas," Physiological Research, vol. 50, no. 6, pp. 537-546, 2001.

[2] S. Lenzen, "The mechanisms of alloxan- and streptozotocininduced diabetes," Diabetologia, vol. 51, no. 2, pp. 216-226, 2008.

[3] K. Susztak, K. Sharma, M. Schiffer, P. McCue, E. Ciccone, and E. P. Böttinger, "Genomic strategies for diabetic nephropathy," Journal of the American Society of Nephrology, vol. 14, no. 3, pp. S271-S278, 2003.

[4] G. H. Tesch and T. J. Allen, "Rodent models of streptozotocininduced diabetic nephropathy (methods in renal research)," Nephrology, vol. 12, no. 3, pp. 261-266, 2007.

[5] S. Itagaki, E. Nishida, M.-J. Lee, and K. Doi, "Histopathology of subacute renal lesions in mice induced by streptozotocin," Experimental and Toxicologic Pathology, vol. 47, no. 6, pp. 485491, 1995.

[6] A. G. Farr, J. W. Mannschreck, and S. K. Anderson, "Expression of Ia antigens by murine kidney epithelium after exposure to streptozotocin," American Journal of Pathology, vol. 126, no. 3, pp. 561-568, 1987.

[7] P. Schmezer, C. Eckert, and U. M. Liegibel, "Tissue-specific induction of mutations by streptozotocin in vivo," Mutation Research, vol. 307, no. 2, pp. 495-499, 1994.

[8] M. Hall-Craggs, D. E. Brenner, R. D. Vigorito, and J. C. Sutherland, "Acute renal failure and renal tubular squamous metaplasia following treatment with streptozotocin," Human Pathology, vol. 13, no. 6, pp. 597-601, 1982.

[9] Y. Tay, Y. Wang, L. Kairaitis, G. K. Rangan, C. Zhang, and D. C. H. Harris, "Can murine diabetic nephropathy be separated from superimposed acute renal failure?” Kidney International, vol. 68, no. 1, pp. 391-398, 2005.

[10] M. D. Breyer, E. Bottinger, F. C. Brosius III et al., "Mouse models of diabetic nephropathy," Journal of the American Society of Nephrology, vol. 16, no. 1, pp. 27-45, 2005.

[11] A. R. Kraynak, R. D. Storer, R. D. Jensen et al., "Extent and persistence of streptozotocin-induced DNA damage and cell proliferation in rat kidney as determined by in vivo alkaline elution and BrdUrd labeling assays," Toxicology and Applied Pharmacology, vol. 135, no. 2, pp. 279-286, 1995. 
[12] E. H. Leiter, "Multiple low-dose streptozotocin-induced hyperglycemia and insulitis in C57BL mice: influence of inbred background, sex, and thymus," Proceedings of the National Academy of Sciences of the United States of America, vol. 79, no. 2, pp. 630-634, 1982.

[13] E. H. Leiter, "Differential susceptibility of BALB/c sublines to diabetes induction by multi-dose streptozotocin treatment," Current Topics in Microbiology and Immunology, vol. 122, pp. 78-85, 1985.

[14] S. Sun, Y. Wang, Q. Li, Y. Tian, M. Liu, and Y. Yu, "Effects of benazepril on renal function and kidney expression of matrix metalloproteinase- 2 and tissue inhibitor of metalloproteinase2 in diabetic rats," Chinese Medical Journal, vol. 119, no. 10, pp. 814-821, 2006.

[15] A. A. Like, M. C. Appel, R. M. Williams, and A. A. Rossini, "Streptozotocin-induced pancreatic insulitis in mice morphologic and physiologic studies," Laboratory Investigation, vol. 38, no. 4, pp. 470-486, 1978.

[16] A. A. Like and A. A. Rossini, "Streptozotocin induced pancreatic insulitis: new model of diabetes mellitus," Science, vol. 193, no. 4251, pp. 415-417, 1976.

[17] A. A. Rossini, M. C. Appel, R. M. Williams, and A. A. Like, "Genetic influence of the streptozotocin-induced insulitis and hyperglycemia," Diabetes, vol. 26, no. 10, pp. 916-920, 1977.

[18] S. B. Gurley, S. E. Clare, K. P. Snow, A. Hu, T. W. Meyer, and T. M. Coffman, "Impact of genetic background on nephropathy in diabetic mice," American Journal of Physiology, vol. 290, no. 1, pp. F214-F222, 2006.

[19] W. Huang, Y. Gallois, N. Bouby et al., "Genetically increased angiotensin I-converting enzyme level and renal complications in the diabetic mouse," Proceedings of the National Academy of Sciences of the United States of America, vol. 98, no. 23, pp. 13330-13334, 2001.

[20] K. Susztak, E. Böttinger, A. Novetsky et al., "Molecular profiling of diabetic mouse kidney reveals novel genes linked to glomerular disease," Diabetes, vol. 53, no. 3, pp. 784-794, 2004.

[21] R. S. Surwit, M. N. Feinglos, J. Rodin et al., "Differential effects of fat and sucrose on the development of obesity and diabetes in C57BL/6J and A/J mice," Metabolism, vol. 44, no. 5, pp. 645-651, 1995.

[22] R. S. Surwit, C. M. Kuhn, C. Cochrane, J. A. McCubbin, and M. N. Feinglos, "Diet-induced type II diabetes in C57BL/6J mice," Diabetes, vol. 37, no. 9, pp. 1163-1167, 1988.

[23] A. E. Petro, J. Cotter, D. A. Cooper, J. C. Peters, S. J. Surwit, and R. S. Surwit, "Fat, carbohydrate, and calories in the development of diabetes and obesity in the C57BL/6J mouse," Metabolism, vol. 53, no. 4, pp. 454-457, 2004.

[24] S. A. Schreyer, D. L. Wilson, and R. C. Leboeuf, "C57BL/6 mice fed high fat diets as models for diabetes-accelerated atherosclerosis," Atherosclerosis, vol. 136, no. 1, pp. 17-24, 1998.

[25] D. A. Towler, M. Bidder, T. Latifi, T. Coleman, and C. F. Semenkovich, "Diet-induced diabetes activates an osteogenic gene regulatory program in the aortas of low density lipoprotein receptor-deficient mice," Journal of Biological Chemistry, vol. 273, no. 46, pp. 30427-30434, 1998.

[26] J. Mu, J. K. Naggert, K. L. Svenson et al., "Quantitative trait loci analysis for the differences in susceptibility to atherosclerosis and diabetes between inbred mouse strains C57BL/6J and C57BLKS/J," Journal of Lipid Research, vol. 40, no. 7, pp. 13281335, 1999.

[27] M. Sugano, H. Yamato, T. Hayashi et al., "High-fat diet in lowdose-streptozotocin-treated heminephrectomized rats induces all features of human type 2 diabetic nephropathy: a new rat model of diabetic nephropathy," Nutrition, Metabolism and Cardiovascular Diseases, vol. 16, no. 7, pp. 477-484, 2006.

[28] S. Makino, K. Kunimoto, Y. Muraoka, Y. Mizushima, K. Katagiri, and Y. Tochino, "Breeding of a non-obese, diabetic strain of mice," Jikken Dobutsu, vol. 29, no. 1, pp. 1-13, 1980.

[29] C. E. Mathews, "Utility of murine models for the study of spontaneous autoimmune type 1 diabetes," Pediatric Diabetes, vol. 6, no. 3, pp. 165-177, 2005.

[30] L. S. Wicker, G. Chamberlain, K. Hunter et al., "Fine mapping, gene content, comparative sequencing, and expression analyses support Ctla4 and Nramp1 as candidates for Idd5.1 and Idd5.2 in the nonobese diabetic mouse," Journal of Immunology, vol. 173, no. 1, pp. 164-173, 2004.

[31] J. P. Driver, D. V. Serreze, and Y. Chen, "Mouse models for the study of autoimmune type 1 diabetes: a NOD to similarities and differences to human disease," Seminars in Immunopathology, vol. 33, no. 1, pp. 67-87, 2011.

[32] T. Doi, L. Y. C. Agodoa, T. Sato et al., "Glomerular lesions in nonobese diabetic mouse: before and after the onset of hyperglycemia," Laboratory Investigation, vol. 63, no. 2, pp. 204212, 1990.

[33] C. E. Alpers and K. L. Hudkins, "Mouse models of diabetic nephropathy," Current Opinion in Nephrology and Hypertension, vol. 20, no. 3, pp. 278-284, 2011.

[34] M. P. Cohen, G. T. Lautenslager, and C. W. Shearman, "Increased urinary type IV collagen marks the development of glomerular pathology in diabetic d/db mice," Metabolism, vol. 50, no. 12, pp. 1435-1440, 2001.

[35] K. Arakawa, T. Ishihara, A. Oku et al., "Improved diabetic syndrome in C57BL/KsJ-db/db mice by oral administration of the $\mathrm{Na}^{+}$-glucose cotransporter inhibitor T-1095," British Journal of Pharmacology, vol. 132, no. 2, pp. 578-586, 2001.

[36] R. Mishra, S. N. Emancipator, C. Miller, T. Kern, and M. S. Simonson, "Adipose differentiation-related protein and regulators of lipid homeostasis identified by gene expression profiling in the murine $\mathrm{db} / \mathrm{db}$ diabetic kidney," American Journal of Physiology, vol. 286, no. 5, pp. F913-F921, 2004.

[37] D. Koya, M. Haneda, H. Nakagawa et al., "Amelioration of accelerated diabetic mesangial expansion by treatment with a PKC $\beta$ inhibitor in diabetic $\mathrm{db} / \mathrm{db}$ mice, a rodent model for type 2 diabetes," FASEB Journal, vol. 14, no. 3, pp. 439-447, 2000.

[38] D. H. Moralejo, T. Ogino, M. Zhu et al., "A major quantitative trait locus co-localizing with cholecystokinin type A receptor gene influences poor pancreatic proliferation in a spontaneously diabetogenic rat," Mammalian Genome, vol. 9, no. 10, pp. 794-798, 1998.

[39] R. Choi, B. H. Kim, J. Naowaboot et al., "Effects of ferulic acid on diabetic nephropathy in a rat model of type 2 diabetes," Experimental and Molecular Medicine, vol. 43, no. 12, pp. 676683, 2011.

[40] P. Li, H. Zhang, F. J. Burczynski et al., "Attenuation of diabetic nephropathy in Otsuka long-evans Tokushima fatty (OLETF) rats with a combination of Chinese herbs (tangshen formula)," Evidence-Based Complementary and Alternative Medicine, vol. 2011, Article ID 613737, 8 pages, 2011.

[41] A. O. Phillips, K. Baboolal, S. Riley et al., "Association of prolonged hyperglycemia with glomerular hypertrophy and renal basement membrane thickening in the Goto Kakizaki model of non-insulin-dependent diabetes mellitus," American Journal of Kidney Diseases, vol. 37, no. 2, pp. 400-410, 2001. 
[42] S. G. Riley, R. A. Evans, M. Davies, J. Floege, and A. O. Phillips, "Goto-Kakizaki rat is protected from proteinuria after induction of anti-Thyl nephritis," American Journal of Kidney Diseases, vol. 39, no. 5, pp. 985-1000, 2002.

[43] S. G. Riley, R. Steadman, J. D. Williams, J. Floege, and A. O. Phillips, "Augmentation of kidney injury by basic fibroblast growth factor or platelet-derived growth factor does not induce progressive diabetic nephropathy in the Goto Kakizaki model of non-insulin-dependent diabetes," Journal of Laboratory and Clinical Medicine, vol. 134, no. 3, pp. 304-312, 1999.

[44] N. Sato, K. Komatsu, and H. Kurumatani, "Late onset of diabetic nephropathy in spontaneously diabetic GK rats," American Journal of Nephrology, vol. 23, no. 5, pp. 334-342, 2003.

[45] Y. Yamamoto, I. Kato, T. Doi et al., "Development and prevention of advanced diabetic nephropathy in RAGEoverexpressing mice," Journal of Clinical Investigation, vol. 108, no. 2, pp. 261-268, 2001.

[46] S. C. Chua Jr., W. K. Chung, X. S. Wu-Peng et al., "Phenotypes of mouse diabetes and rat fatty due to mutations in the OB (leptin) receptor," Science, vol. 271, no. 5251, pp. 994-996, 1996.

[47] S. M. Clee, S. T. Nadler, and A. D. Attie, "Genetic and genomic studies of the BTBR ob/ob mouse model of type 2 diabetes," American Journal of Therapeutics, vol. 12, no. 6, pp. 491-498, 2005.

[48] K. L. Hudkins, W. Pichaiwong, T. Wietecha et al., "BTBR Ob/Ob mutant mice model progressive diabetic nephropathy," Journal of the American Society of Nephrology, vol. 21, no. 9, pp. 1533$1542,2010$.

[49] K. A. Melez, L. C. Harrison, J. N. Gilliam, and A. D. Steinberg, "Diabetes is associated with autoimmunity in the New Zealand Obese (NZO) mouse," Diabetes, vol. 29, no. 10, pp. 835-840, 1980.

[50] D. Lu, D. Willard, I. R. Patel et al., "Agouti protein is an antagonist of the melanocyte-stimulating-hormone receptor," Nature, vol. 371, no. 6500, pp. 799-802, 1994.

[51] M. M. Ollmann, B. D. Wilson, Y. Yang et al., "Antagonism of Central Melanocortin receptors in vitro and in vivo by agoutirelated protein," Science, vol. 278, no. 5335, pp. 135-138, 1997.

[52] M. Okazaki, Y. Saito, Y. Udaka et al., "Diabetic nephropathy in KK and KK-Ay mice," Experimental Animals, vol. 51, no. 2, pp. 191-196, 2002.

[53] H. Ninomiya, T. Inomata, and K. Ogihara, "Obstructive uropathy and hydronephrosis in male KK-Ay mice: a report of cases," Journal of Veterinary Medical Science, vol. 61, no. 1, pp. 53-57, 1999.

[54] M. S. Phillips, Q. Liu, H. A. Hammond et al., "Leptin receptor missense mutation in the fatty Zucker rat," Nature Genetics, vol. 13, no. 1, pp. 18-19, 1996.

[55] Y. Li, Y. Qi, M. S. Kim et al., "Increased renal collagen crosslinking and lipid accumulation in nephropathy of Zucker diabetic fatty rats," Diabetes/Metabolism Research and Reviews, vol. 24, no. 6, pp. 498-506, 2008.

[56] S. Hoshi, Y. Shu, F. Yoshida et al., "Podocyte injury promotes progressive nephropathy in zucker diabetic fatty rats," Laboratory Investigation, vol. 82, no. 1, pp. 25-35, 2002.

[57] T. M. Coimbra, U. Janssen, H. J. Gröne et al., "Early events leading to renal injury in obese Zucker (fatty) rats with type II diabetes," Kidney International, vol. 57, no. 1, pp. 167-182, 2000.

[58] Y. Izuhara, T. Sada, H. Yanagisawa et al., "A novel sartan derivative with very low angiotensin II type 1 receptor affinity protects the kidney in type 2 diabetic rats," Arteriosclerosis,
Thrombosis, and Vascular Biology, vol. 28, no. 10, pp. 1767-1773, 2008.

[59] A. B. Magil and J. J. Frohlich, "Monocytes and macrophages in focal glomerulosclerosis in Zucker rats," Nephron, vol. 59, no. 1, pp. 131-138, 1991.

[60] A. B. Magil, "Tubulointerstitial lesions in young zucker rats," American Journal of Kidney Diseases, vol. 25, no. 3, pp. 478-485, 1995.

[61] D. Chen and M. Wang, "Development and application of rodent models for type 2 diabetes," Diabetes, Obesity and Metabolism, vol. 7, no. 4, pp. 307-317, 2005.

[62] J. L. Figarola, S. Loera, Y. Weng, N. Shanmugam, R. Natarajan, and S. Rahbar, "LR-90 prevents dyslipidaemia and diabetic nephropathy in the Zucker diabetic fatty rat," Diabetologia, vol. 51, no. 5, pp. 882-891, 2008.

[63] W. P. Cui, B. Li, Y. Bai et al., "Potential role for Nrf2 activation in the therapeutic effect of MG132 on diabetic nephropathy in OVE26 diabetic mice," American Journal of Physiology, vol. 304, no. 1, pp. E87-E99, 2013.

[64] S. Zheng, W. T. Noonan, N. S. Metreveli et al., "Development of late-stage diabetic nephropathy in OVE26 diabetic mice," Diabetes, vol. 53, no. 12, pp. 3248-3257, 2004.

[65] J. Xu, Y. Huang, F. Li, S. Zheng, and P. N. Epstein, "FVB mouse genotype confers susceptibility to OVE26 diabetic albuminuria," American Journal of Physiology, vol. 299, no. 3, pp. 487494, 2010.

[66] H. J. Zhao, S. Wang, H. Cheng et al., "Endothelial nitric oxide synthase deficiency produces accelerated nephropathy in diabetic mice," Journal of the American Society of Nephrology, vol. 17, no. 10, pp. 2664-2669, 2006.

[67] S. Mohan, R. L. Reddick, N. Musi et al., "Diabetic eNOS knockout mice develop distinct macro- and microvascular complications," Laboratory Investigation, vol. 88, no. 5, pp. 515528, 2008.

[68] F. C. Brosius III, C. E. Alpers, E. P. Bottinger et al., "Mouse models of diabetic nephropathy," Journal of the American Society of Nephrology, vol. 20, no. 12, pp. 2503-2512, 2009.

[69] R. Inagi, Y. Yamamoto, M. Nangaku et al., "A severe diabetic nephropathy model with early development of nodule-like lesions induced by megsin overexpression in RAGE/iNOS transgenic mice," Diabetes, vol. 55, no. 2, pp. 356-366, 2006.

[70] M. Maeda, A. Yabuki, S. Suzuki, M. Matsumoto, K. Taniguchi, and H. Nishinakagawa, "Renal lesions in spontaneous insulindependent diabetes mellitus in the nonobese diabetic mouse: acute phase of diabetes," Veterinary Pathology, vol. 40, no. 2, pp. 187-195, 2003.

[71] C.-J. He, F. Zheng, A. Stitt, L. Striker, M. Hattori, and H. Vlassara, "Differential expression of renal AGE-receptor genes in NOD mice: possible role in nonobese diabetic renal disease," Kidney International, vol. 58, no. 5, pp. 1931-1940, 2000.

[72] O. G. Pankewycz, J. Guan, W. K. Bolton, A. Gomez, and J. F. Benedict, "Renal TGF- $\beta$ regulation in spontaneously diabetic NOD mice with correlations in mesangial cells," Kidney International, vol. 46, no. 3, pp. 748-758, 1994.

[73] K. Sharma and F. N. Ziyadeh, "Renal hypertrophy is associated with upregulation of TGF- $\beta 1$ gene expression in diabetic BB rat and NOD mouse," American Journal of Physiology, vol. 267, no. 6, part 2, pp. F1094-F1101, 1994.

[74] F. Y. Chow, D. J. Nikolic-Paterson, E. Ozols, R. C. Atkins, and G. H. Tesch, "Intercellular adhesion molecule-1 deficiency is protective against nephropathy in type 2 diabetic $\mathrm{db} / \mathrm{db}$ mice," 
Journal of the American Society of Nephrology, vol. 16, no. 6, pp. 1711-1722, 2005.

[75] F. R. DeRubertis, P. A. Craven, M. F. Melhem, and E. M. Salah, "Attenuation of renal injury in $\mathrm{db} / \mathrm{db}$ mice overexpressing superoxide dismutase: evidence for reduced superoxide-nitric oxide interaction," Diabetes, vol. 53, no. 3, pp. 762-768, 2004.

[76] K. Shima, K. Shi, T. Sano, T. Iwami, A. Mizuno, and Y. Noma, "Is exercise training effective in preventing diabetes mellitus in the Otsuka-Long-Evans-Tokushima Fatty rat, a model of spontaneous non-insulin-dependent diabetes mellitus?" Metabolism, vol. 42, no. 8, pp. 971-977, 1993.

[77] N. Okauchi, A. Mizuno, S. Yoshimoto, M. Zhu, T. Sano, and K. Shima, "Is caloric restriction effective in preventing diabetes mellitus in the Otsuka Long Evans Tokushima Fatty Rat, a model of spontaneous non-insulin-dependent diabetes mellitus?" Diabetes Research and Clinical Practice, vol. 27, no. 2, pp. 97-106, 1995.

[78] U. Janssen, A. Vassiliadou, S. G. Riley, A. O. Phillips, and J. Floege, "The quest for a model of type II diabetes with nephropathy: the Goto Kakizaki rat," Journal of Nephrology, vol. 17, no. 6, pp. 769-773, 2004.

[79] F. Miralles and B. Portha, "Early development of beta-cells is impaired in the GK rat model of type 2 diabetes," Diabetes, vol. 50, pp. S84-88, 2001.

[80] M. T. Velasquez, P. L. Kimmel, and O. E. Michaelis IV, "Animal models of spontaneous diabetic kidney disease," FASEB Journal, vol. 4, no. 11, pp. 2850-2859, 1990.

[81] F. Bielschowsky and M. Bielschowsky, "The New Zealand strain of obese mice; their response to stilboestrol and to insulin," Australian Journal of Experimental Biology \& Medical Science, vol. 34, no. 3, pp. 181-198, 1956.

[82] E. H. Leiter and P. C. Reifsnyder, "Differential levels of diabetogenic stress in two new mouse models of obesity and type 2 diabetes," Diabetes, vol. 53, no. 1, pp. S4-S11, 2004.

[83] P. C. Reifsnyder and E. H. Leiter, "Deconstructing and reconstructing obesity-induced diabetes (diabesity) in mice," Diabetes, vol. 51, no. 3, pp. 825-832, 2002.

[84] J. P. Corsetti, J. D. Sparks, R. G. Peterson, R. L. Smith, and C. E. Sparks, "Effect of dietary fat on the development of noninsulin dependent diabetes mellitus in obese Zucker diabetic fatty male and female rats," Atherosclerosis, vol. 148, no. 2, pp. 231-241, 2000. 


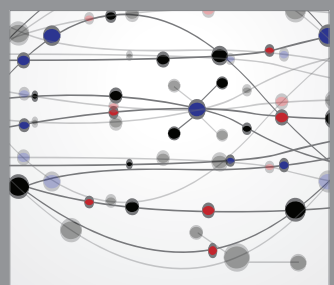

The Scientific World Journal
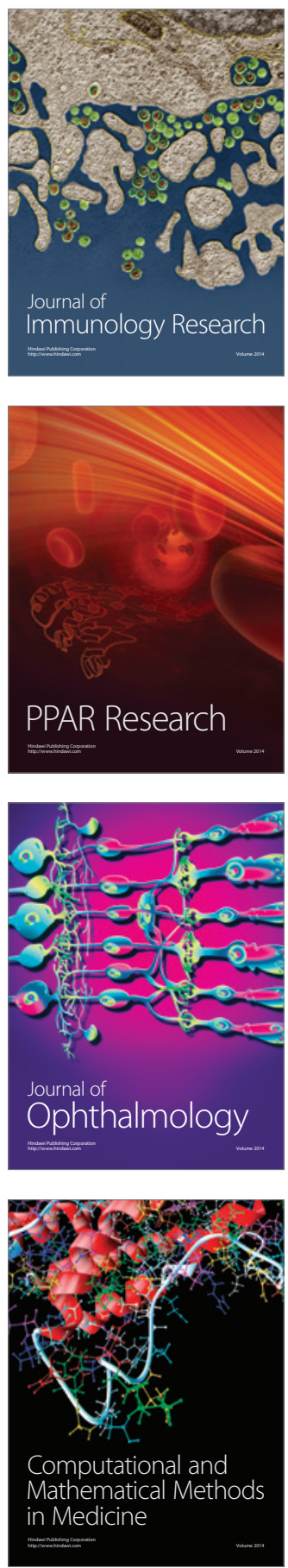

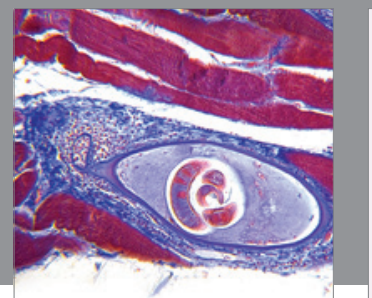

Gastroenterology

Research and Practice
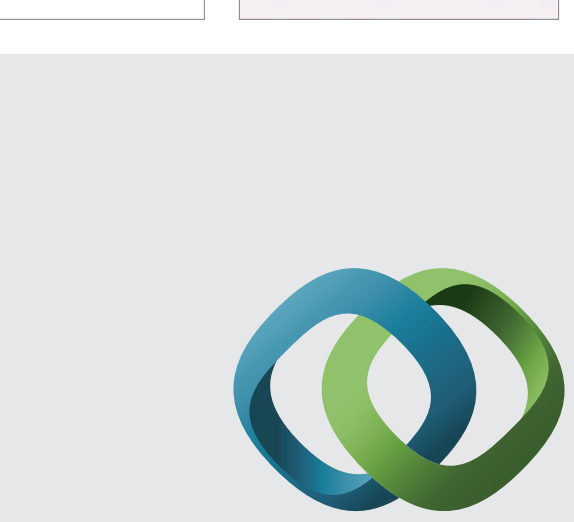

\section{Hindawi}

Submit your manuscripts at

http://www.hindawi.com
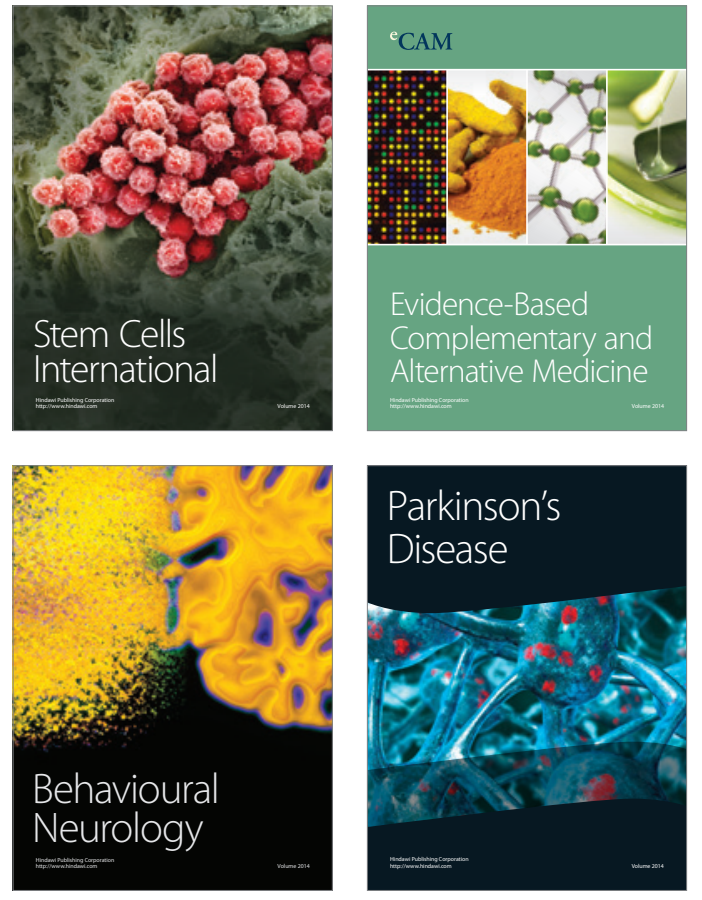
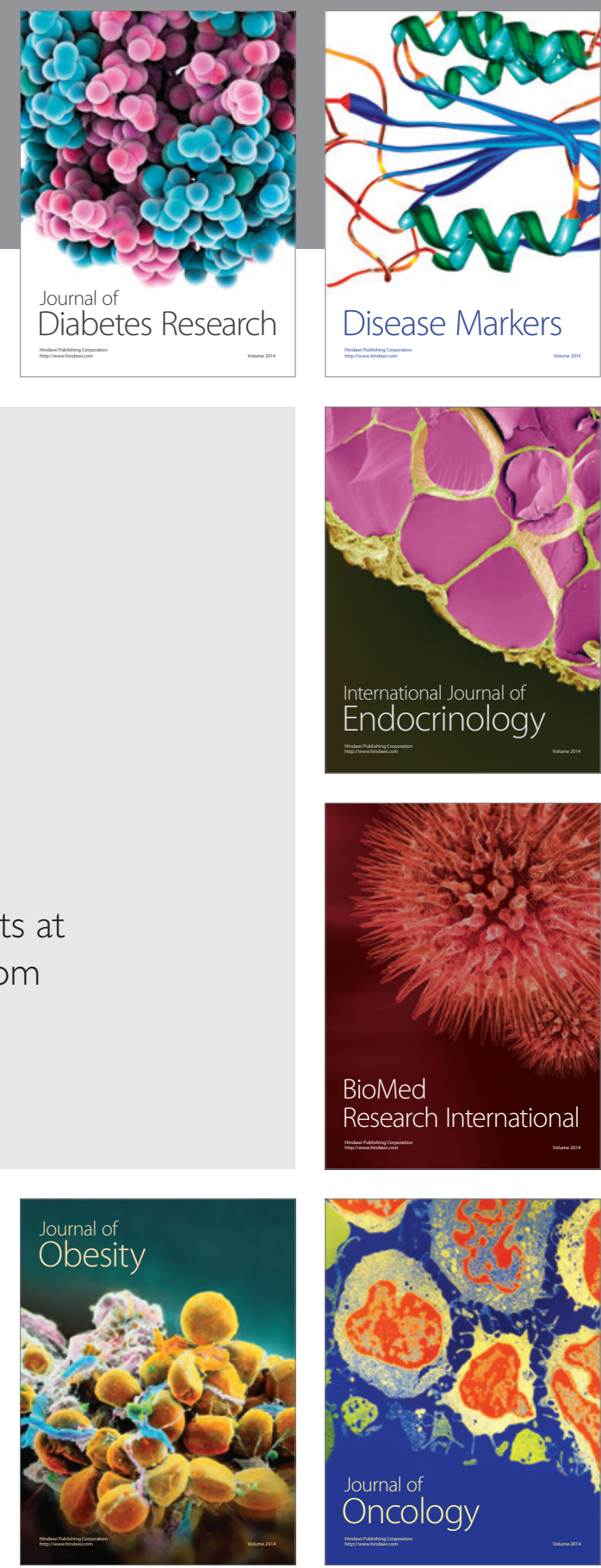

Disease Markers
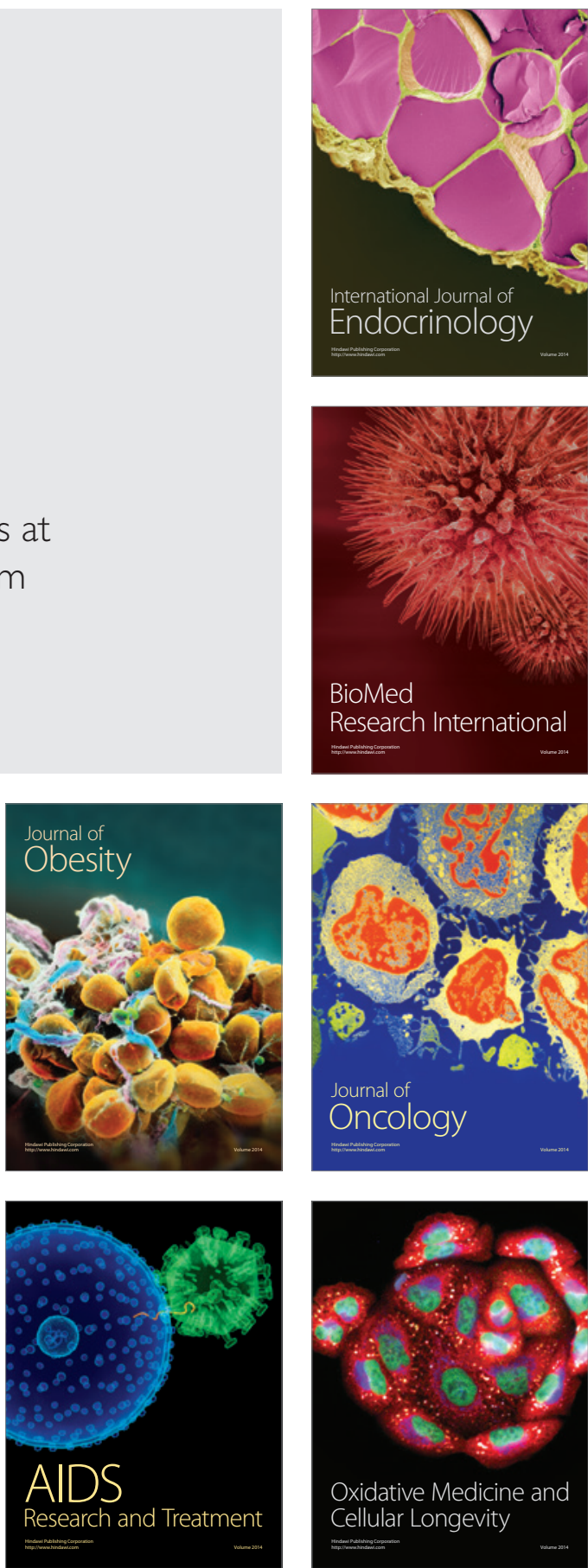